\title{
The Low Cost Carrier Revolution Continues: Evidence From The US Airline Industry
}

Bogdan Daraban, Shenandoah University, USA

\begin{abstract}
Over the past twenty years the US airline industry has been marked by the intense competition between the Low-Cost Carriers (LCCs) and the Full-Service Carrier (FSCs). The fundamental differences between the two business models are reflected in considerable cost advantages of the LCCs. In this paper, I use a set of model specific metrics to investigate whether the competitive process has led to convergence in some of the key features of the competing models. I conclude that despite some evidence of convergence along certain dimensions, the LCCs are not ready to abandon the core LCC model.
\end{abstract}

Keywords: Low Cost Carriers; Airline Competition

\section{INTRODUCTION}

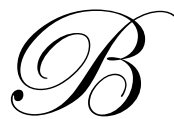

y fully liberalizing pricing, market entry, and scheduling, the Airline Deregulation Act of 1978 changed the US airline industry in fundamental ways. One of the most important developments in the post-deregulation era was the successful emergence of the low cost carrier (LCC) business model.

Pioneered by Southwest Airlines as early as 1971, when competition was limited to intrastate markets, the LCC model is characterized by certain features that result in low operating costs relative to the full service carrier (FSC) model. The LCC model can be succinctly described as featuring no-frills passenger service within a point-to-point network of short and medium-haul routes that serve secondary airports, using a highly productive homogenous fleet. On the other hand, the 'legacy carriers', often referred to as 'full-service carriers' or 'network carriers', operate huband-spoke networks, deploying multiple aircraft types in short and long-haul routes, and offering a higher class product overall.

Over time, the LCC model was adopted with different degrees of success by numerous other airlines in the US and abroad. Its success in the US is evident from the impressive growth of the passenger market share of the LCCs, from $16 \%$ in 1993 to $36 \%$ in 2010 (based on author's calculations using the Bureau of Transportation Statistics Airline Origin and Destination Survey (DB1BMarket) (BTS, 2011a)). It is not surprising therefore, that the impact of the LCCs on the US airline industry is well documented. A 1996 report by the Department of Transportation proclaimed that the US airline industry was undergoing a 'low cost airline service revolution' that would have 'a profound effect on efficiency, competition, consumers and industry structure.' That a revolution was indeed under way was confirmed by findings that LCCs lowered airfares not only in the markets where they actually entered (Morrison, 2001; Windle \& Dresner, 1995), but also in nearby markets (Daraban \& Fournier, 2008; Dresner, Lin, \& Windle, 1996), and in markets where they were well positioned for future entry (Goolsbee \& Syverson, 2006). Overall, virtually all empirical studies point to significantly lower airfares and higher passenger volumes brought about by the LCC revolution.

In addition to documenting the effects of LCCs on the US airline industry, industry observers were also concerned with the sources of this revolution and when and how it would end. By the mid 1990s it was obvious that the industry was witnessing a clash between two business models based on very different concepts. Furthermore, the contrast between the two approaches materialized in very different cost structures unit cost differentials. Fare levels, 
pricing dynamics and the cost heterogeneity in the industry showed that the industry had not reached the long run competitive equilibrium. More adjustments in the cost structure, prices and other features of the business models were expected. Graf (2005) documented the failed attempts by the FSCs to establish low cost spin-offs to compete with the LCCs and concluded that the two models are incompatible within the same airline grouping. Bogulaski, Ito and Lee (2004) provided evidence that during the 1990s, a shift took place in the expansion pattern of Southwest Airlines' route system. While Franke (2005) predicted the need for a substantial restructuring of the FSC model, the prevailing view was that an equilibrium would be reached with both models in existence, complementing each other, or that a hybrid model would result. For example, Alderighi, Cento, Nijkamp, and Rietveld (2005) employ a gametheoretical framework to show that for large markets, the only possible equilibria are consistent with the coexistence of the point-to-point and the hub-and-spoke models specific to the LCCs and the FSCs respectively.

Recently, it has become apparent that the adjustments resulting from the competition between LCCs and FSCs could potentially result in convergence to a state where the once sharp distinction between the two models becomes increasingly blurred. Airline Business (2008) pointed out different ways in which carriers labeled as 'low cost' broke the mould of the original monolithic low cost model and how it is increasingly difficult to properly define the LCC model, which now describes 'what has become a huge variety of subtly varying business models.' For example, some LCCs have started offering some frills on their flights, or business class fares. More importantly, the nature of their networks seems to be changing as they operate longer-haul flights, between airports they were initially avoiding (e.g. legacy hubs), with an increased reliance on connecting flights and sometimes even hub airports. These observations are however, anecdotal in nature as the current literature lacks a rigorous, systematic study of these claims. This paper is an attempt to fill the void in the literature by documenting in more detail the hypothesized convergence between the LCC and the FSC business models by comparing them along several dimensions. Doing so can offer valuable insights into the current and future state of the US airline industry. Moreover, the results of this paper are particularly relevant for understanding future developments in the airline markets around the world where the LCC revolution started later.

The rest of the paper is organized as follows: The next section contrasts the features of the original LCC model with those of the FSC model. I then present quantitative evidence of the convergence between the two competing models and conclude in the last section.

\section{A COMPARISON OF THE CORE LOW COST AND THE FULL SERVICE BUSINESS MODELS}

Despite the observed increase in the degree of heterogeneity among the LCCs, there are certain key features that can be identified as the core of the original, consecrated LCC model. Doganis (2010) provides a detailed account of these features and how they contribute to the lower unit operating costs that led to the extraordinary success of the LCC model. The discussion below is based in part on Doganis' (2010) analysis of the core LCC model pioneered by Southwest Airlines. Southwest Airlines was the first truly low-cost airline that started expanding its operations right after deregulation. Over the years it grew constantly, and while its pricing strategies were aggressive, Southwest Airlines is the only airline in the U.S. that remained profitable every year since its inception. Southwest's business strategy was soon followed by other carriers such as Value Jet (Air Tran after 1998), American Trans Air (ATA), Frontier and America West to name a few. The number of LCCs started to grow fast especially during the 1990s.

The most important element that distinguishes the LCC and the FSC models is the network structure. The FSCs, also known as 'network' or 'legacy' carriers, complex operate hub-and-spoke networks that allow them to achieve maximum connectivity for as many demand categories as possible (i.e. take anyone from anywhere to everywhere), consistent with the 'full service' label. They achieve this by concentrating departures and arrivals at certain hub airports, as close as possible in time, to increase the probability of connecting outbound flights with inbound flights (Ben-Yosef, 2005). Operating hub-and-spoke networks delivers important cost efficiencies associated with economies of density and scope. Moreover, hub dominance by the FSCs can potentially facilitate strategic entry deterrence (Borenstein, 1989). On the other hand, the hub-and-spoke networks are more likely to incur costs associated with delays, low and fluctuating utilization rates for aircraft and ground workforce and slow turnaround. 
In contrast to the FSCs, the original business strategy of the LCCs was simple and focused. They essentially identified the coverage-convenience trade-off that characterizes the industry and took a different approach by tipping the balance in favor of simple and efficient production processes at the cost of connectivity and network coverage. The early LCCs provided simple, no-frills services, without free meals, narrow seating (greater capacity), no seat reservation and no frequent-flyer programs. An essential feature of the early LCCs was their tendency to operate short-haul and medium-haul point-to-point routes with high frequencies and to use secondary airports. Connectivity was not the focus anymore, but it was still essential as a byproduct of the point-to-point system. Such a system allowed for quick turnarounds and a highly productive use of aircraft and personnel. Moreover, flexible non-stop scheduling increased passenger convenience. As a result, LCCs were able to compete for both the low and high-paying market segments by offering low prices and a quality product in the form of nonstop flights with fewer restrictions. The LCCs mainly focused on under-served or over-priced markets, and aimed to gain a dominant share in the markets they operated through low fares and high frequency. In addition to being low, their fare structure was simple and unrestricted, with no complex conditions attached. Discounting through specials and more restricted fares was limited.

Several other factors contributed to the low unit costs of the LCCs. The utilization of secondary airports and older terminals reduced airport fees and also, up to a certain point it made it possible to avoid head-on competition with the FSCs carriers. Also, less congested airports reduce average flight times and delay incidents. Consequently LCCs started to attract business travelers who value punctuality and frequency. The deployment of homogeneous fleets resulted in savings with maintenance, cockpit training and standby crews. Other important features of the early LCCs include innovative boarding processes that yielded shorter ground waits, no air freight, no hub services, short cleaning times and a lean sales force due to greater reliance on online sales. Labor costs represent an important cost category in the airline industry, accounting for about one third of total operating costs. Keeping these costs under control can make a big difference with respect to the financial viability of the airlines. Strong unions and more rigid institutional arrangements and agreements prevented the FSCs from achieving the labor cost efficiencies of the LCCs. On the other hand, the LCCs benefited from flexible and highly motivated workers who were often given a vested interest through profit sharing programs.

Overall, the simple, focused approach of the LCCs allows them to enjoy competitive features that are reflected in low unit costs that the FSCs find extremely hard to match. However, Doganis (2010) notes that in the 2000s the LCCs started to depart from the simple LCC model of Southwest Airlines. For example, the initial strategy of Southwest Airlines was to stimulate market demand by serving secondary airports and becoming the major player in selected markets. In contrast, Jet Blue's strategy is based on entry in dense markets without becoming the leader. AirTran and Frontier offer two fare classes, while JetBlue provides leather seats, in-flight entertainment and entered international routes. In the next section I investigate the extent to which such departures are evident in the data and whether they are also reflected in performance measures.

\section{METRICS FOR THE LCC AND FSC BUSINESS MODELS}

In order to explore the extent to which the LCCs and the FSCs are becoming more similar, I use a set of metrics constructed to capture some of the key features of the two competing business models. All metrics were constructed using data from the Bureau of Transportation Statistics (BTS) between 1993 and 2010 for three groups of carriers: the FSCs ${ }^{1}$, all $\mathrm{LCCs}^{2}$ and a select subset of all LCCs (first eight carriers in the list of all LCCs). For the purpose of this study, I compiled the list of LCCs based on existing studies of the LCC phenomenon (US Department of Transportation, 1996; Ito \& Lee, 2003), the current classification employed by the Bureau of Transportation Statistics and my assessment of airline specific data on operating costs. The select group of LCCs includes the most successful carriers in terms of market share.

\footnotetext{
${ }^{1}$ Alaska Airlines, Continental, Delta, Northwest (merged into Delta by the end of 2009), US Airways, and United Airlines

2 JetBlue (2000-), Frontier (1994 - ), AirTran (1994 - ) America West (1983 - 2007), Spirit Lines (1992 - ), Southwest (1979 - ), Allegiant (2000 - ), Virgin America (2007-), ValuJet (1993 - 2000), Morris (1992 - 1994), Kiwi (1992 - 2000$)$, National (1999 2002), Vanguard (1994 - 2002), Pro Air (1997 - 2000), Reno (1992 - 1999), Horizon (1984 - ), Sun Country (1999 - 2004), ATA (1981 - 2008), Western Pacific (1995 - 1998), Eastwind (1995 - 1999), South Air (1994 - 1997),Carnival (1991 - 1998$).$
} 


\section{Labor force related metrics}

Employee productivity. Available seat miles (miles flown times the number of seats available) divided by the total number of employees is used as an approximation of employee productivity. According to Virgin Blue's head of strategic development, "Really only two things [are universal for low-cost carriers]: people productivity and asset productivity." (Airline Business, 2008). Figure 1 confirms the expectation that overall, the LCCs have a higher employee productivity, mainly due to the point-to-point structure of their networks which allows them to use personnel and aircraft more efficiently. Moreover, the gap between LCCs and FSCs is widening, which contradicts the model convergence argument. This indicates that even if the LCCs are tweaking some features of their business model, they do it in a manner that does not affect one of the most important measures of performance: the productivity of their employees.

Employee compensation. Labor represents one of the most important single cost items for the airline industry. Figure 2 compares average quarterly salary and benefits per employee for the three groups of carriers. According to this measure, the LCCs enjoyed a substantial cost advantage over their competitors in particular between 1995 and 2005. It would be wrong however to attribute the success of the LCC model entirely to the labor cost differential. During the period under examination, labor costs incurred by Southwest Airlines, the most successful LCC, were in fact very close to and higher than those of the FSCs. This is consistent with the efficiency wage argument according to which high pay leads to more motivated and productive workers. At the same time, Southwest's unionized labor force might be driving the recent increases. Two factors can explain the overall convergence between compensation levels: Going through bankruptcy protection allowed the FSCs to cut costs across the board and re-negotiate labor compensation agreements. On the other hand, the LCCs have been subject to seniority related increases in labor costs. Given this convergence, it will be interesting to observe how the pricing power of the LCCs will be affected in the near future.

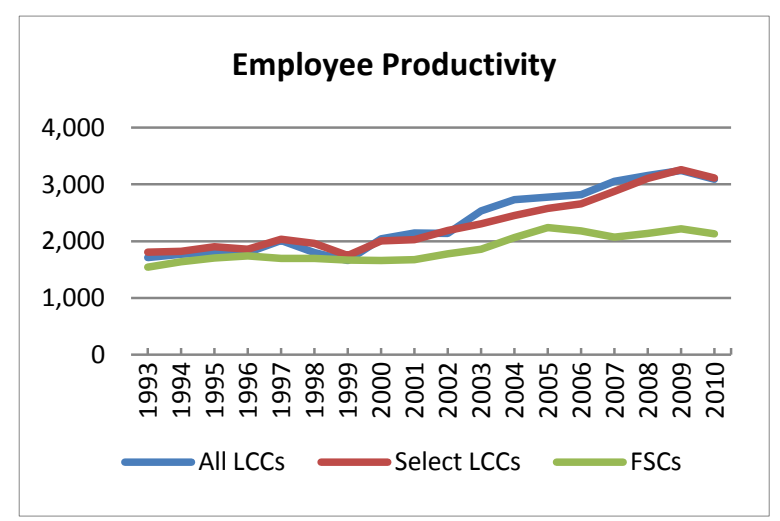

Figure 1 Employee productivity measured as available seat miles per employee. Calculated using BTS (2011b) Air Carrier Summary Data (T2) and BTS (2011c) Air Carrier Financial Reports (P-10)



Figure 2 Average salary and benefits in thousands of dollars. Calculated using BTS (2011c) Air Carrier Financial Reports (P-6 and P-10)

\section{Network structure and operations}

Average stage length. Average stage length for an airline is defined as the average distance flown on non-stop trips. The core LCC model, as pioneered by Southwest, is based on short- and medium-haul flights that allow quick turnaround times. There are however important exceptions from this pattern. For example, relatively new LCCs like JetBlue and Virgin America flew non-stop distances longer than 1,000 miles from the very beginning. This can be attributed in part to the increased availability of adequate aircraft and the increased presence of LCCs at international vacation destinations. On the other hand, Southwest has been only slowly increasing the average length of their non-stop flights and is currently at the bottom of the distribution according to this measure. Figure 3 
illustrates how the LCCs have been expanding their networks by entering longer haul routes. It remains to be seen whether this departure from the core model will be reflected in productivity, cost and pricing power.

Percentage of connecting passengers. As discussed in the previous section, the competition between FSCs and LCCs is ultimately carried out between the point-to-point and the hub-and-spoke network structures. It is evident from Figure 4 that non-stop flights remain the hallmark of the LCC business model. Although some LCCs such as JetBlue and AirTran use hub-like focus airports in New York City and Atlanta, respectively, the overwhelming majority of LCC passengers fly non-stop. Moreover, following the recent acquisition of AirTran, Southwest plans to diminish the role of Atlanta as a connecting hub, therefore showing its commitment to the core low-cost model (Yamanouchi, 2011).

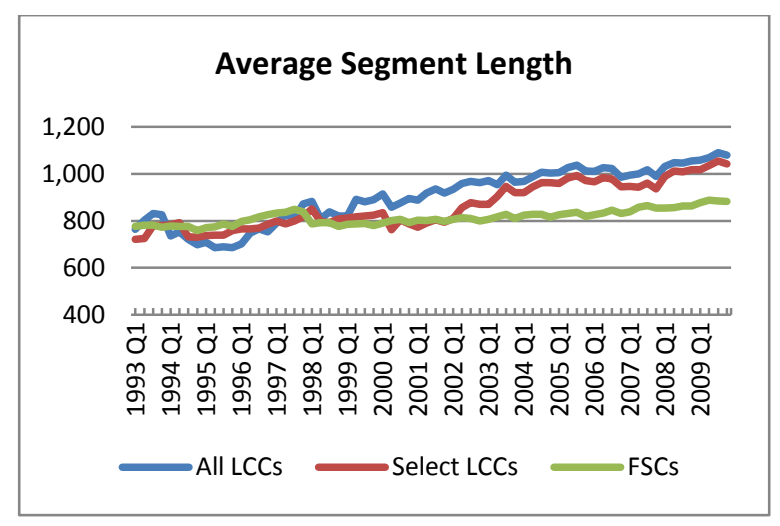

Figure 3 Average distance flown on non-stop trips, measured in miles. Calculated using the BTS (2011a) Airline Origin and Destination Survey (DB1BMarket) database.



Figure 4 Percent of connecting passengers. Calculated using the BTS (2011a) Airline Origin and Destination Survey (DB1BMarket) database.

Airport-level enplanements. Two apparently contradictory forces determine which airports the LCCs choose to serve. They try to avoid costly delays by using less congested secondary airports, while focusing on denser markets that are profitable in the context of point-to-point networks. Figure 5 shows the average size of the airports served by the three groups of carriers, in terms of quarterly total enplanements. As expected, in looking for new profit opportunities, the LCCs attempted to expand more aggressively into larger airports, in particular in the second half of the 1990s. This pattern was short-lived however, as it reflected expansion attempts by smaller LCCs that were unsuccessful and ultimately went bankrupt. The reasons for such exits are beyond the scope of this paper. Possible explanations can include aggressive responses of the incumbents, in particular in hub airports, as well as reduced performance due to departing from the core LCC model. Although steadily increasing, the lower average airport size served by the FSCs can be explained by the relatively large number of small airports that can be served economically using hub-and-spoke networks. It is also apparent that the FSCs have been eliminating such airports from their networks. Overall, there is evidence that the two models are converging with respect to this metric.

Number of Aircraft Types. Fleet homogeneity is often cited as contributor to the low unit cost of the LCCs. Figure 6 confirms that the LCCs continue to maintain much more homogenous fleets than the FSCs. At the same time, although the gap between the two models remains large and it cannot go away due to the different network structures, the FSCs' fleets are become more homogenous as well. 


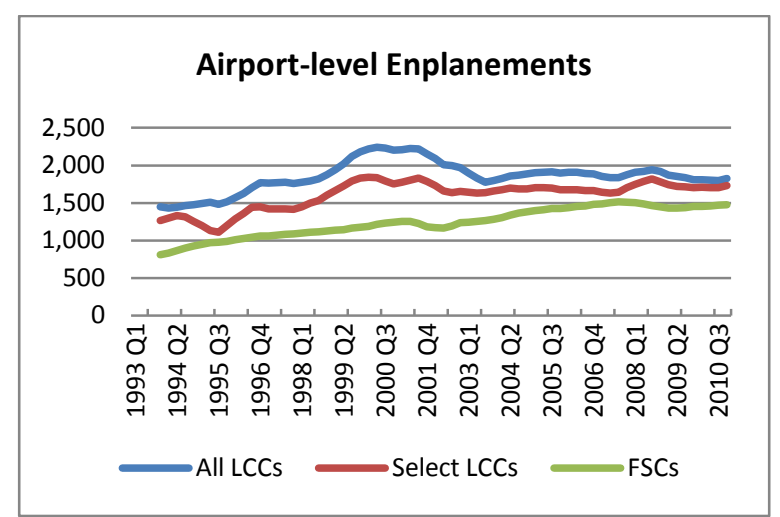

Figure 5 Average total enplanements at airports served. Calculated using BTS (2011a) Airline Origin and Destination Survey (DB1BMarket) database.

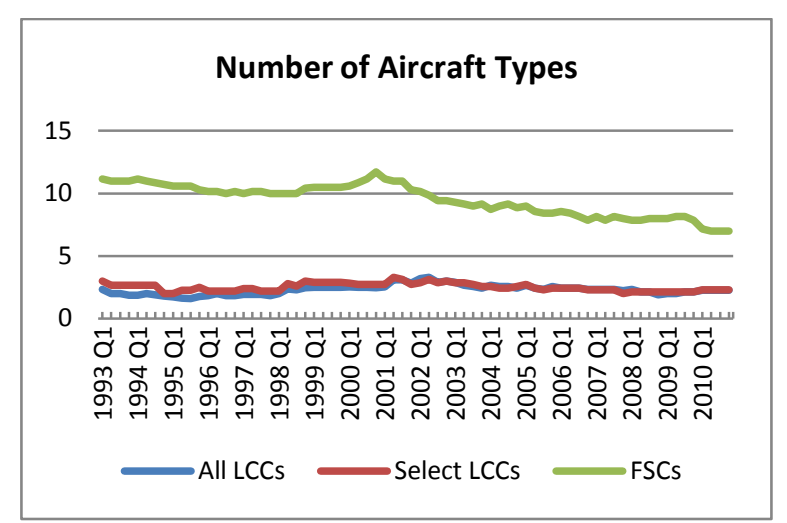

Figure 6 Number of aircraft types. Calculated using BTS (2011a) Airline Origin and Destination Survey (DB1BMarket) database.

\section{Pricing}

Fare Dispersion. Through yield management practices that Borenstein and Rose (1994) define as the 'dynamic allocation of discount seats to maximize revenue on each flight', the FSCs have created complicated pricing structures, with complex conditions attached to them. On the other hand, the core LCC model uses simple and unrestricted fare schedules. Figure 7 confirms the much lower fare dispersion levels among the LCCs. A steady increase can be observed for the LCCs, with the route level standard deviation increasing by approximately $50 \%$ between 2004 and 2010. The result is in large part driven by the entry of JetBlue and Virgin American in 2000 and 2007 respectively. The fare dispersion measure for Southwest followed the same trend. It remains to be seen if the move away from the simple fare structure will negatively affect costs.

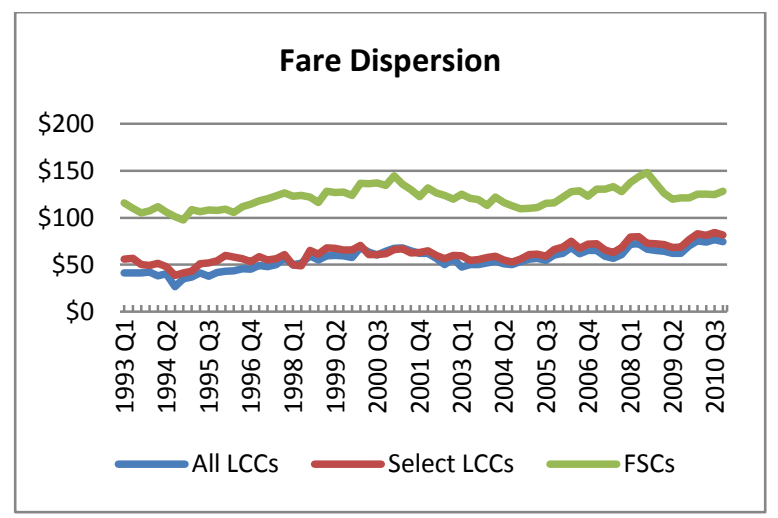

Figure 7 Standard deviation of route level fares. Calculated using BTS (2011a) Airline Origin and Destination Survey (DB1BMarket) database.



Figure 8 Total operating expenses per available seat mile. Calculated using BTS (2011b) Air Carrier Summary Data (T2) and BTS (2011c) Air Carrier Financial Reports (P-1.2).

\section{Cost per Available Seat Mile}

The key features of the two competing models are ultimately reflected in the cost structure. The most widely used industry measure is cost per available seat mile, calculated as total operating expenses divided by available seat miles. It is evident from Figure 8 that not only are cost levels associated with the two business models not converging, but the gap is still widening. Although not the lowest cost airline, Southwest remains cost 
competitive when compared to the FSCs and the other LCCs. In 2010, all LCCs incurred unit costs that were within a range of 2 cents per available seat mile. This suggests that despite the ever increasing number of ways in which they attempt to differentiate themselves from each other, the existing LCCs have converged towards a core model that compared to the FSCs ensures considerably lower unit costs.

\section{CONCLUSIONS}

The LCC business model has been reshaping the US airline industry for the past twenty years. This paper provides evidence that along certain dimensions, a process of convergence has been taking place between the competing LCC and FSC business models. For example, the FSCs have been able to cut employee compensation through drastic restructuring efforts facilitated by bankruptcy protection, while the LCCs have been incurring increased legacy labor costs. At the same time, the airports served by the two groups of carriers are becoming more similar in size, while the LCCs' fares exhibit more dispersion as a result of the adoption of yield management practices specific to the FSCs. On the other hand, no such convergence is observed for the more essential features that distinguish the two models. The employees of the LCCs are increasingly more productive than those of the FSCs. Also, there is no indication that the LCCs are ready to abandon their focus on non-stop service, and their reliance on homogenous fleets. Since these differences stem mainly from the fundamentally contrasting network structures, it is unlikely that they will disappear in the near future. Most importantly the remaining differences between the two models are reflected in a still widening unit cost gap. This suggests that the industry has not yet reached equilibrium and significant resource allocation issues remain to be resolved.

On the surface, it might seem that as new LCCs have been entering the industry, a variety of new business models is emerging. However, the analysis provided in this paper demonstrates that although the LCCs face strong incentives to differentiate themselves from the competition, they are not abandoning the key features of the core LCC model. Therefore, moving forward, the equilibrium outcome depends on the response of the FSCs. Until then, the LCC revolution in the US airline industry continues.

\section{AUTHOR INFORMATION}

Dr. Bogdan Daraban earned his PhD in Economics from Florida State University and is currently Assistant Professor of Economics in the Harry F. Byrd, Jr. School of Business at Shenandoah University. His research interests include applied microeconomics with a focus on industrial organization issues in the airline industry, and the pedagogy of economics. He has published in Research in Transportation Economics, The Journal of Gambling Studies and The Journal of Education for Business. E-mail: bdaraban@ @u.edu

\section{REFERENCES}

1. Airline Business (2008, May 19). Low-cost carriers become harder to define. Airline Business. Retrieved from http://www.flightglobal.com.

2. Alderighi, M., Alessandro, C., Peter, N., \& Rietveld, P. (2005). Network Competition - the Coexistence of Hub-and-Spoke and Point-to-Point Systems. Journal of Air Transport Management 11, 328-334.

3. Ben-Yosef, E. (2005). The Evolution of the U.S. Airline Industry. Dordrecht, the Netherlands: Springer

4. Bogulaski, C., Ito, H., \& Lee, D. (2004). Entry patterns in the Southwest airlines route system. Review of Industrial Organization, 25(3), 317-350.

5. Borenstein, S. (1989). Hubs and high fares: dominance and market power in the US airline industry. RAND Journal of Economics, 20, 344-365.

6. Borenstein, S. \& Rose, N. L. (1994). Competition and Price Dispersion in the U.S. Airline Industry. Journal of Political Economy, 102(4), 653-83

7. Bureau of Transportation Statistics. (2011a). Airline origin and destination survey. Retrieved from http://www.transtats.bts.gov.

8. Bureau of Transportation Statistics. (2011b). Air Carrier Summary Data. Retrieved from http://www.transtats.bts.gov.

9. Bureau of Transportation Statistics. (2011c). Air Carrier Financial Reports. Retrieved from http://www.transtats.bts.gov. 
10. Dresner, M. E., Lin, J. S.-C., \& Windle, R. J. (1996). The impact of low cost carriers on airport and route competition. Journal of Transport Economics and Policy, 30(3), 309-328.

11. Goolsbee, A., \& Syverson, C. (2008). How do incumbents respond to the threat of entry? Evidence from major airlines. Quarterly Journal of Economics, 123(4), 1611-1633.

12. Daraban B., \& Fournier, G. (2008). Incumbent Responses to Low Cost Airline Entry and Exit: A Spatial Autoregressive Panel Data Analysis. Research in Transportation Economics, 24, 15-24.

13. Doganis, R. (2010). Flying Off Course IV: Airline Economics and Marketing. Routledge.

14. Field, D. (2008, April 24). Low cost carriers tweak their models. Airline Business. Retrieved from http://www.flightglobal.com.

15. Franke, M. (2004). Competition Between Network Carriers and Low-cost Carriers-Retreat Battle or Breakthrough to a New Level of Efficiency?. Journal of Air Transport Management 10, 15-21

16. Graf, L. (2005). Incompatibilities of the Low-Cost and Network Carrier Business Models within the Same Airline Grouping. Journal of Air Transport Management, 11, 313-327.

17. Morrison, S. A. (2001). Actual, adjacent and potential competition. Estimating the full impact of Southwest Airlines. Journal of Transport Economics and Policy, 35(2), 239-256.

18. Whinston, M. D., \& Collins, S. C. (1992). Entry and competitive structure in deregulated airline markets: an event study analysis of People Express. RAND Journal of Economics, 23(4), 445-462.

19. Windle, R. J., \& Dresner, M. E. (1995). The short and long run effects of entry on US domestic air routes. Transportation Journal, 35(2), 14-25.

20. Windle, R. J., \& Dresner, M. E. (1999). Competitive responses to low cost carrier entry. Transportation Research Part E, 35, 59-75.

21. US Department of Transportation. (1996). The Low Cost Airline Service Revolution. Retrieved from http://ostpxweb.dot.gov/aviation/Data/lowcostrevo.pdf.

22. Yamanouchi, K. (2011, November 13). Southwest begins transforming AirTran flight schedule. The Atlanta Journal-Constitution. Retrieved from http://ww.ajc.com. 